\title{
Implementing pedagogies of care in online teacher education
}

\author{
Dewa Wardak \\ The University of Sydney
}

\begin{abstract}
Research shows that students who believe their teachers are caring for them are more likely to engage with the class and exhibit higher levels of self-esteem and well-being. What we learn from the past should guide our present practice to pave the way for a more authentic relationship with our students in the future. This paper reports a case study of how a 'pedagogy of care' was implemented in a first-year large teacher-education unit of study at an Australian university during the transition to fully online learning and teaching in response to the pandemic. The paper reports the strategies adopted by the teaching team and the results of an online survey conducted with the students about their experience of the transition. The qualitative survey responses were organised into themes that illustrated how students perceived teacher care. According to the students, teachers cared when they organised consistent synchronous sessions, provided opportunity for interaction between students, recorded lectures, were lenient, modified assessment, marked assessments quickly, exhibited positivity, and acknowledged challenges due to COVID-19. These themes were then classified into two broad categories on a continuum ranging between the delivery of the unit to interpersonal or human aspects.
\end{abstract}

Keywords: pedagogy of care; teacher education; rethinking education; post-pandemic pedagogy

\section{Introduction}

In response to COVID-19 restrictions in March 2020, many educational institutions across Australia and around the world pivoted to online learning and teaching. The pandemic has highlighted the need for improving our teaching practices and a move away from a teacher-centred model that was designed for the brick-and-mortar university to a more inclusive student-centred approach that can engage students at a distance. According to Ferdig and Pytash (2021) "We must see 2020 as an opportunity for an educational revolution. We are thinking of 'revolution' from the Latin revolutio, meaning "a turn around". We, as teacher educators, must turn around how we envision teaching and learning" (p.9). In this paper, an argument is made for a return to a "pedagogy of care' for the future of higher education. What we learn from the past should guide our present practice to pave the way for a more authentic relationship with our students in the future that is based on a 'pedagogy of care'.

At the University of Sydney, a first-year large core teacher-education unit of study had to suddenly transition to fully online mode in Week 4 of Semester 12020 when one of the first cases of COVID-19 was detected in the student cohort. This transition was particularly impactful as the majority of the students in this unit were also transitioning from high school to university. The teaching team for this unit made several pedagogical decisions which revolved around reducing uncertainties for students, meeting the needs of the diverse student cohort which included a large number of international students who arrived only days before the restrictions were introduced in the country, and implementing a pedagogy of care in an online context. Navigating these challenges required a team approach with some of the strategies implemented at a higher level such as modifying the assessments and some at a local level such as tutors checking in on students during the weekly tutorials.

This paper describes how a 'pedagogy of care' was implemented to ease the transition to online learning for first-year teacher education students and share the results of an online survey conducted with the students in this unit in Week 12 of the semester. The paper starts with a brief overview of what care means in higher education and refers to some of the strategies adopted by teachers during the pandemic to help students studying online. This is followed with a background to the case study, which includes a description of the strategies adopted by 
the teaching team to ease the transition of students to fully online learning and teaching. The results of the survey focus on the perceived care and students' awareness of the implementation of a 'pedagogy of care' in this unit. The paper concludes with a discussion of the results, limitations of the study, and significance of the findings, followed by discussing how educators can move forward in a post-COVID world and explicitly ground their teaching practices in care.

\section{What is care in education?}

As an educator, I ascribe to Nel Noddings' (2012) 'pedagogy of care' and agree that education is more than academic success and we will not achieve that "success unless our children believe that they themselves are cared for and learn to care for others" (Noddings, 1995, p.675). The aim of this 'pedagogy of care' is to ensure that students are aware that they are cared for. Past research has shown that if students believe that their teachers are caring for them, they are more likely to engage with the class, put more effort in, and evaluate their teacher more positively (Teven \& McCroskey, 1997). More recent research shows that students who feel their teacher is caring for them exhibit higher levels of self-esteem and well-being, and this in return influences how meaningful the teacher finds his/her job (Lavy \& Naama-Ghanayim, 2020). Teacher care is especially important for at-risk students who benefit from knowing that their teachers are interested, expect them to succeed, listen to them, praise their effort, and care (Muller, 2001). Implementing policies that care for students' psychological and social well-being, not just academic achievement, can improve student behaviour (Doyle \& Doyle, 2003).

\section{Teacher care during COVID-19}

A pedagogy of care can be manifested in many different pedagogical strategies. Nasr (2020) identified two main features of 'pedagogy of care' relevant to online learning during COVID-19. The first was conducting synchronous classes to support teacher-student connectedness, facilitate the sharing of experiences and reflect the challenges of online learning. The second was flexibility in providing support for her secondary science students who were experiencing challenges related to the pandemic, such as losing jobs and family issues. Fackler and Sexton (2020) analysed online posts to a university teacher-educators Facebook group for trends related to how science teacher educators negotiated the shift from face-to-face instruction to online learning. They identified several themes including reporting how a teacher education program modified the field experience component of their program and how the teachers adopted interactive tools to engage students online. These strategies were adopted in order to reduce the pressure on students while transitioning to online learning during the pandemic, hence showing students that they care. Many educators have reported how they modified their tasks and assessments in response to COVID-19 and the sudden transition to online learning. For instance, Brown (2020), reported how she modified a science teacher-educator assessment to comply with COVID-19 restrictions while allowing students to perform exploration of the outside environment for their research tasks. Vasquez (2020) similarly reported how she modified laboratory tasks for the online environment, so her Anatomy and Physiology students didn't have to purchase expensive material and equipment for their home science kits.

\section{The case study}

A case study is an approach to educational research that aims to "capture the complexity of relationships, beliefs and attitudes within a bounded unit, using different forms of data collection" (Hamilton \& Corbett-Whittier, 2012, p.10). This paper reports the results of a case study on the pedagogical design of a unit of study and the experiences of students in one tutorial group during the transition to online learning in response to COVID-19 restrictions. The focus is on the perceived care by the students during the transition process.

\section{Background}

In March 2020, students in an undergraduate first-year teacher-education core unit at the University of Sydney had to suddenly transition to fully online learning within a week. For many students, this unit is their first experience at university and an introduction to their teaching degree. There were over 400 students enrolled in this unit and a large number of them were international students. When the semester started, some of the international students were still in quarantine as the Australian government had just introduced a two-weeks isolation for newly arrived international visitors, particularly those coming from China. As a result, several of the students in this unit missed face-to-face classes during the first two weeks of the semester. It was during 
Week 3 of the semester when one of the first COVID-19 cases was identified amongst the student cohort and the faculty decided to quickly transition to online teaching and learning. While some units were more prepared than others, the main concern for all teacher-educators was the wellbeing of the students. The eleven-member teaching team for this unit quickly began devising several strategies to lessen the pressure on the students while transitioning to online learning. It was particularly important to consider the well-being of these students since they were still transitioning from high school to university and the sudden pivot to online learning could have been detrimental to their wellbeing and success at university.

\section{How care was implemented in this unit}

One of the first strategies the unit coordinators devised was to modify a group assessment and remove the presentation aspect. Normally this assessment involves students working in groups and choosing an educator of the year, which could include individuals, groups, or organisations they believed deserved to be acknowledged for their contribution to education. The assessment includes a group presentation, which is normally the fun aspect for students as each group is also trying to gain the best-presentation vote from their peers. The teaching team deemed that this assessment would place students under a lot of pressure to collaborate with other students and make a presentation online, while they were still learning how to use online tools such as Zoom. The second strategy was to immediately move to synchronous online tutorials for all students enrolled in the unit. This transition was very rapid, and all tutorials were delivered through Zoom in Week 4. The teaching team was also cognisant that this sudden transition would not be easy for many students, so the third strategy was to implement multiple ways of checking in on students. This last strategy was implemented slightly differently by each tutor.

The following were some strategies implemented in one of the tutorial groups where the tutor checked in on students to show them that their tutor cared about their wellbeing, help them deal with isolation, and motivate them throughout the semester.

Each tutorial started with a reflection on the past week and the tutor encouraged students to focus on something positive. For instance, the tutor asked each student to talk about one act of kindness they received or how they made someone smile in the past week. Some students had multiple stories to share. While these experiences were shared verbally with the entire class, the tutor also made sure to provide opportunities where students anonymously shared how they felt. For instance, the tutor provided a link to a question on AnswerGarden where students described their mid-semester break in one word, see Figure 1. The word cloud compiled on AnswerGarden then formed the base of the discussion in the tutorial.

\section{Describe your mid-semester break in one word.}

\section{Type your answer here...}

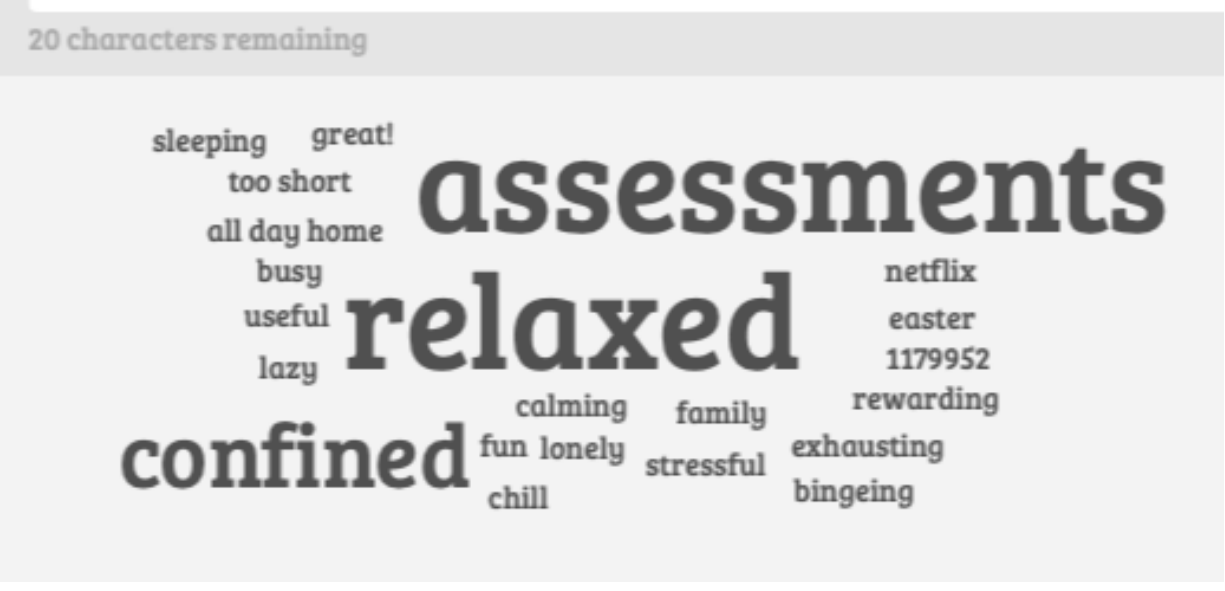

Figure 1. AnswerGarden responses

In addition to checking in on students during the synchronous tutorials, the tutor also provided opportunities to connect with the students through asynchronous discussion boards where students shared various non-study related posts. For instance, the students were asked to share photos of something that made them happy, 
something cute or simply what they were doing that day. Some of the photos shared are illustrated in Figure 2. Research indicates that a caring relationship between teacher and students is not considered to be one-way but depends on the students' reciprocal responses (Kim \& Schallert, 2011). In this unit, the students responded to the pedagogies of care, for instance by engaging with the activities in the class and posting their photos, stories, and funny TikTok videos on the discussion board online.
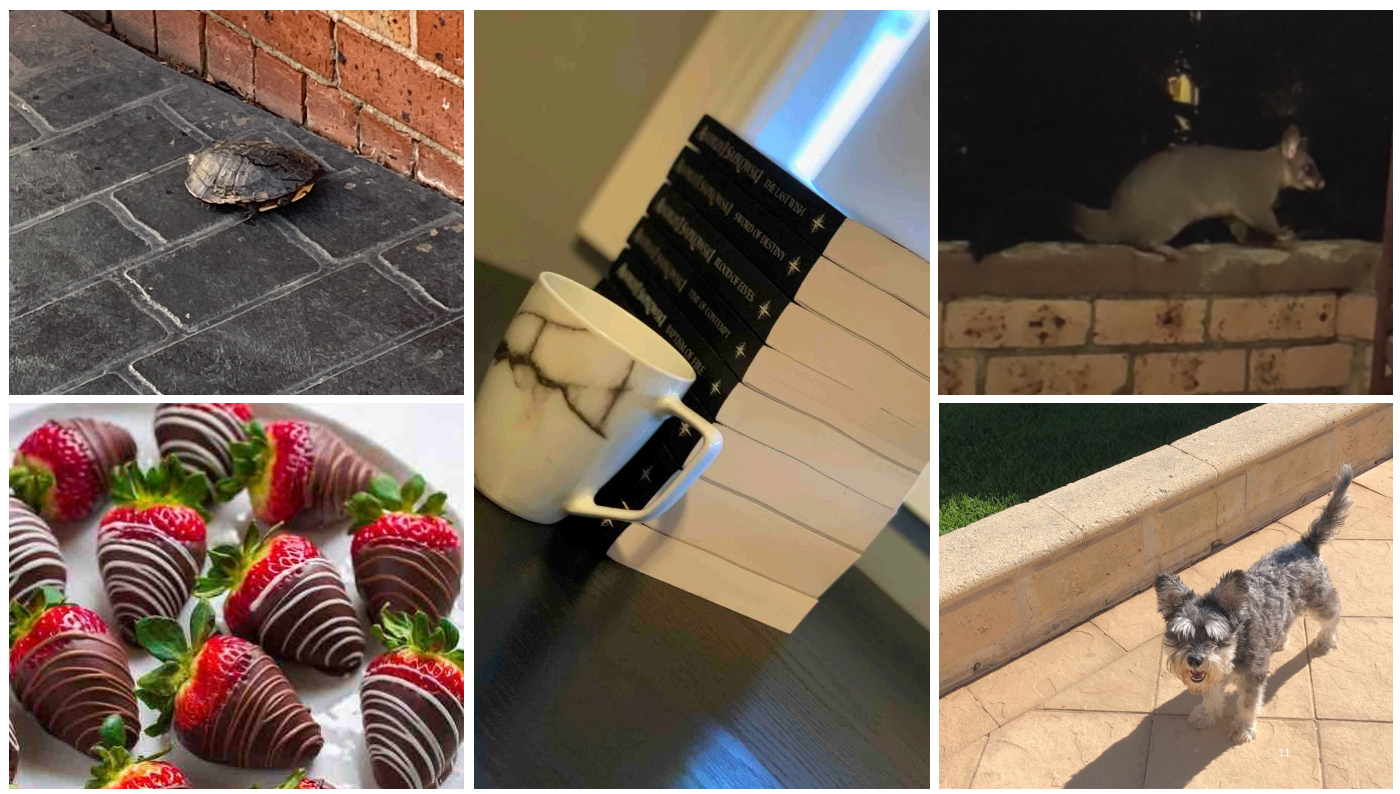

Figure 2. Students and teacher posts shared on the discussion board

\section{The Survey}

The students in this unit remained highly engaged after the sudden transition to online learning in Week 4 of the semester. With the aim of getting a better understanding of the students' experience and what they deemed important or helpful in transitioning to online learning during their first year at university, a survey was designed and implemented. After being granted ethics approval to conduct this study, data was collected at the end of Week 12 Semester 12020 through an anonymous online survey hosted on Qualtrics. The survey was implemented in one tutorial group and all 32 students responded. The survey included 15 questions with a mix of Likert scale, multiple choice, and open-ended questions. These included some demographic questions such as asking students if this was their first time studying at the university and studying online, how they would rate the transition to online learning, if they preferred online or face-to-face lectures, and whether they found online learning complicated.

The three main opening-ended questions asked the students to 1) describe their learning experience during the semester, 2) how they experienced the transition to online learning, and 3) if they had a similar experience with their other units of study. Students had the freedom to not answer any of the questions in the survey. The qualitative data gathered through these open-ended questions was uploaded to NVivo and analysed using thematic analysis, which involves a search for themes that emerge inductively from the data. The process involved a six-stage approach which included familiarization with the data, followed by coding, searching for themes, reviewing the preliminary themes, defining the themes by giving them descriptive names, and writing up the themes or categories (Clarke \& Braun, 2013).

\section{Survey Results}

The survey included some basic demographic questions. Around $75 \%$ or 24 out of 32 respondents indicated that this was their first year at university. When asked if they have studied in a fully online mode before, almost $91 \%$ or 29 out of 32 responded No. Around $74 \%$ or 20 out of 27 responded that they preferred face-to-face tutorials. Students were further asked to indicate their level of agreement with a number of statements (see Figure 3). The most positive aspect was that the majority of students strongly agreed or somewhat agreed that the transition to online learning in this unit was well organised and ran smoothly. The majority of students also indicated that 
they were moving in a systematic and organised manner with their studies. When asked about their preference for lecture mode, the majority indicated that they preferred face-to-face lectures. While students mostly agreed that studying online is not complicated, they indicated that it might take more time.

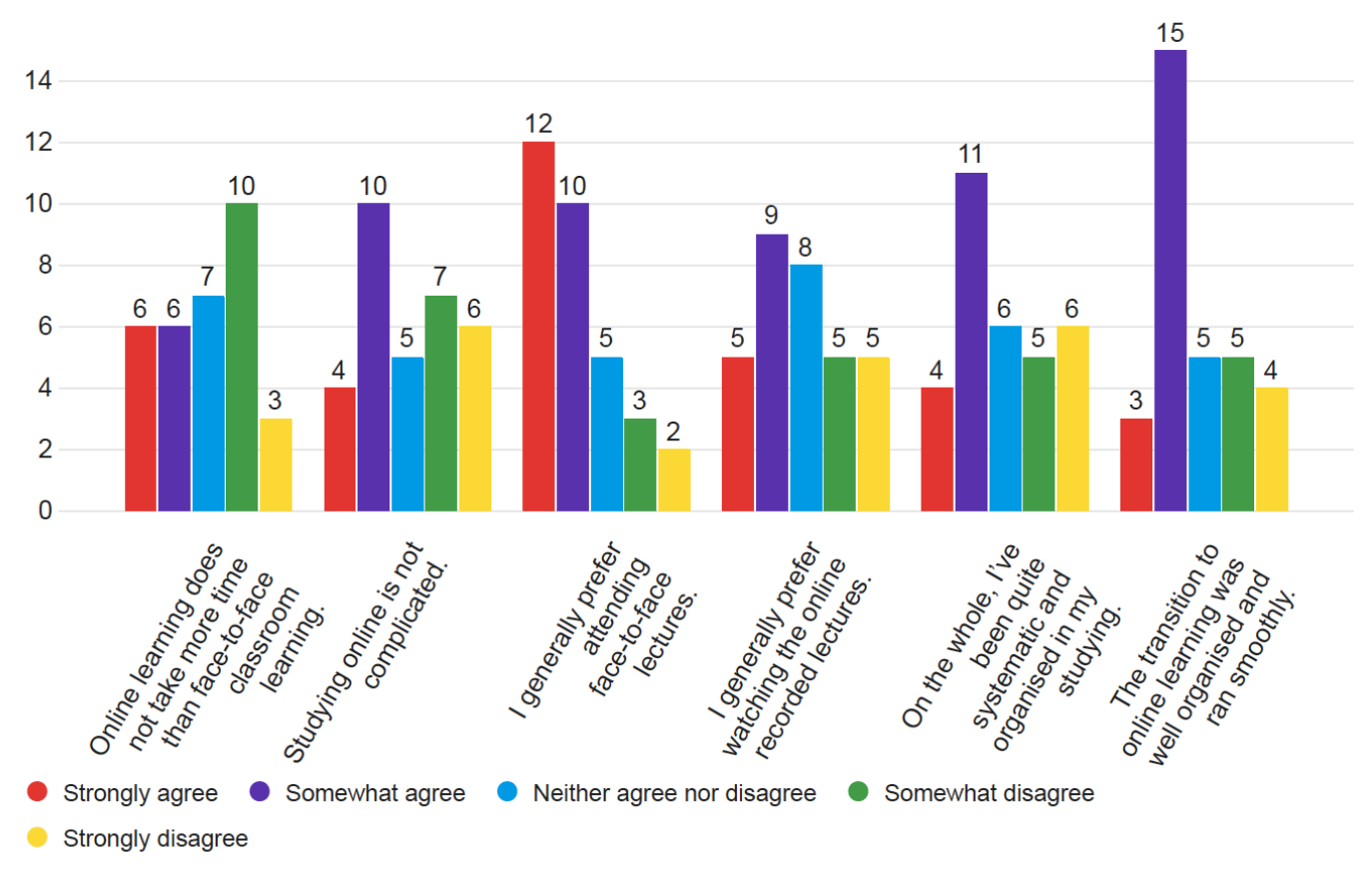

Figure 3. Quantitative survey results

\section{Student feelings}

The analysis of the qualitative data indicated that students were feeling a range of emotions during the sudden transition to online learning. These included being scared, confused, frustrated, and going through a difficult time. Students indicated that the uncertainty made them feel scared with one student commenting 'I did not expect any of this was going to happen' and another stating 'this is not how I anticipated my first year to be'.

Some of the frustrations the students were feeling also involved their families. For instance, one student stated 'it was very challenging and hard as I am an international student, with the amount of school fees that my parents pay and learning under such circumstances [is hard]'. Some students were frustrated because their home environments were not suited to studying and this made it difficult for them, as one student indicated 'I wouldn't be as disturbed in face-to-face tutorials because all of my family members were at home making it difficult for me to focus, e.g., coming in my room not knowing I was in a zoom meeting or playing music or TV loudly downstairs'. A number of students had mixed feelings, and some acknowledged that there were both positive and negative aspects with studying online. For instance, one response to the question asking about their experience during the semester stated:

Quite different from what I expected it to be. We were lucky that we got to go to uni for the first three weeks, introduce ourselves and at least make some friends in classes. I am happy that I don't have to wake up early to travel to uni, which often takes a lot of time and money, however, I do end up procrastinating a lot.

And finally, students felt that there was hope for next semester once they get through these difficulties with one response stating, 'just hope that I could possibly get through this semester and next one would be better, online learning has really been quite hard for me'.

\section{Types of perceived care by students}

As stated above, perceived care is one of the main aspects of 'pedagogy of care' and is supported by research in 
this area indicating that it is important that the students know that their teachers care for their learning and their wellbeing (Lavy \& Naama-Ghanayim, 2020; Muller, 2001; Noddings, 1995; Teven \& McCroskey, 1997). Steered by this line of research, the qualitative analysis searched for comments that indicated students' awareness of teacher care. Since students were not directly asked about this aspect in the survey, finding many comments, some directly referencing 'care' and how it helped them during the semester, was surprising. The data related to this aspect was then coded into the following broad themes. The students believed that teachers cared when they organised consistent synchronous zoom sessions, provided access to online recorded lectures, provided opportunity for interaction, were lenient, marked assessments quickly, modified assessment to make it easier for students, exhibited positivity, and acknowledged challenges due to the COVID-19 pandemic. Below is a more detailed explanation of these themes with reference to student comments.

Theme 1 - Synchronous sessions:

This was one of the major themes as several students commented on how having synchronous sessions indicated teacher care because otherwise the student would fall behind. In the survey when asked if the students had a similar experience in other units one student responded:

No, it was very different. I felt that [this unit] was the unit that really cared for my learning through consistent zoom tutorials each week while my other units were vague with what was going to happen to our tutorials and such.

In this comment, clear communication is also mentioned as important to enable the students to follow the weekly process. The weekly Zoom session provided an opportunity for students to ask questions and be informed about how the unit was progressing. Students also indicated that the weekly synchronous sessions acted as motivation and a form of accountability that prevented them from falling behind, as one student responded to the question asking if they had a similar experience in other units:

No. I fell behind pretty easily once there weren't any classes and in units where there are no live zoom tutorials I don't hold myself accountable. I tended to leave lectures until I'd caught up on the VAST amount of reading which I fell behind in with the initial shock of the event and while I scrambled to make my apartment work with two people working from home constantly.

Students indicated that replacing synchronous sessions with another form such as discussion board posts were more difficult and time consuming as one student commented 'I had a more different experience with other units of study as tutorials were replaced with weekly discussion posts on prescribed readings which I found a bit more difficult and time-consuming'.

Theme 2 - Online recorded lectures

One of the strategies adopted by the teaching team in this unit was to record all the live lectures and make them available for students to watch on Canvas. Students appreciated this because they saw it as efficient and avoiding further disruptions. One student commented that the online recorded lectures were 'less time consuming than travelling to university', while another stated that the recorded lectures were 'Convenient \& had more time for myself (reflecting)'.

One student stated: 'One of the best aspects of this course is that we had prepared lectures ahead of time, which provided consistency with our learning (Lesser disruptions)'. The recorded lectures were appreciated because they saved time for other activities including reflection and managing assignments as one student reflected, 'Although online learning was different, it was enjoyable and saved me more time to study properly and manage my assignments'. The recorded lectures formed part of the routine for some students as they 'watched the recorded lectures and did the readings the day before my Zoom tutorial'.

\section{Theme 3 - Opportunity for interaction}

Students' responses to the survey indicated that they appreciated the opportunities where they could connect with their peers during the weekly tutorial lessons. For instance, one student stated: '[this unit] was one of the 2 out of 4 units that offers zoom tutorials which were quite helpful as I had an opportunity to interact with other students and discuss other peoples opinions on a topic'. Another student indicated that they 'found it easier to make more friends through break-out rooms'. The breakout rooms were also mentioned by another student who hated them at first but later started to love them, stating: 
I felt like I made better friends in this class. At first I hated break-out rooms because they made me nervous, but now I actually love them. I liked how we did a lot of little group activities that allowed us to get to know each other.

In this unit, students were often put randomly into breakout rooms for different activities. One student indicated that they liked this aspect because they communicated with students they would not otherwise stating 'I was also able to talk to a larger array of students due to the randomly allocated breakout rooms which forced me to communicate with different people who I wouldn't typically talk to'.

\section{Theme 4 - Teacher positivity}

As stated earlier, there was a deliberate strategy in this unit to be lenient to students, to check on their wellbeing and to notice any inconsistencies with student behaviour. For instance, during Week 7 of the semester one of the students was unusually quiet and would not turn on their camera. The tutor followed the tutorial with an email to the student to check how they were doing and found out that their grandfather had passed away. The students appreciated this care for their wellbeing and one response to the survey stated:

It was definitely hard for me due to the coronavirus having such an impact on my personal life (family member passing away and not being able to travel overseas to be with my family and attend the funeral) but through how much care and positivity shown through my tutor, it really motivated me to become a teacher who embeds so many valuable characteristics like her - which made me to continue to focus on my study despite the hardships.

Theme 5 - Acknowledging challenges

This theme indicated that students preferred that the teachers acknowledged the challenges brought about by the pandemic and recognise that the sudden transition to online learning was hard for the students. One student stated:

I'm quite impressed that the teachers and whoever was involved in preparing with the transition adapted quickly with the sudden situation, they were also really helpful with any questions we had. I appreciate that several teachers acknowledged the difficulty with this transition and highlighted the efforts of the teachers \& students, it somewhat comforted me about the situation, that it will be okay.

Rather than the acknowledgment of challenges and difficulties bringing about panic and anxiety in the students, it prompted a feeling of 'it will be okay'.

\section{Theme 6 - Leniency}

When this unit pivoted to online teaching and learning, the teaching team decided to slowly guide the students not only through managing their studies but also with learning how to use the online tools, such as Zoom. During Weeks 4 and 5, many students missed their Zoom sessions because they were still learning how to use Zoom or had technical issues. The teaching team were lenient towards these students and provided opportunities for them to attend other classes where possible. Some students noticed this leniency and acknowledged that it helped them as they managed their studies and formed a routine for online learning. One student describing their experience in this unit as:

Unique. At first, the transition from high school to university was a bit challenging as the routine was quite different, however, once I was settled things were easy. Then the transition to online studies posed a challenge, once again I got used to the routine and things got easier. However, the staff made it easy to transition and I am very thankful for all the support and leniency provided.

Theme 7 - Marking quickly and modifying assessment

A couple of students referred to how they appreciated that the teachers marked their assignments quickly and also how the unit coordinators modified the assessment to reduce the pressure on the students. One student combined these two ideas in one comment stating:

The fact that assignments in other units weren't marked for weeks resulting in all other dates being pushed back multiple times means I now have around 10 assignments due which I think is unnecessarily overwhelming and works against me doing well or wanting to do well for the stress. 
Especially with the adjusted WAM. [This unit] very quickly removed the group assignment and relieved pressure is such a succinct way I don't see why other subjects refused to ease the workload or the marking.

\section{Interrelations between the themes}

Upon further analysis, the themes were classified under two broad categories on a continuum ranging from the unit delivery to the interpersonal or human aspects. According to this categorisation, the themes synchronous sessions, online recorded lectures, and the strategy for quick marking and modifying assessments are broadly related to how the unit was delivered, while the themes opportunities for peer interaction, teacher positivity, acknowledging challenges, and leniency are related to the interpersonal, or the human aspects of the unit. This further analysis also identified the relationships between the themes as some comments from students indicated interdependence between the strategies adopted by the teaching team. For instance, the synchronous sessions provided opportunity for peer interaction. Acknowledging that students were going through challenges resulted in adopting certain strategies such as providing consistency through recorded lectures, modifying assessment, and marking quickly. Furthermore, it led to being more lenient towards the students which was also linked to teacher positivity. Figure 4 shows how the themes were located on a continuum ranging between the two broad categories: unit delivery and interpersonal aspects. It further illustrates the relationships between the categories.

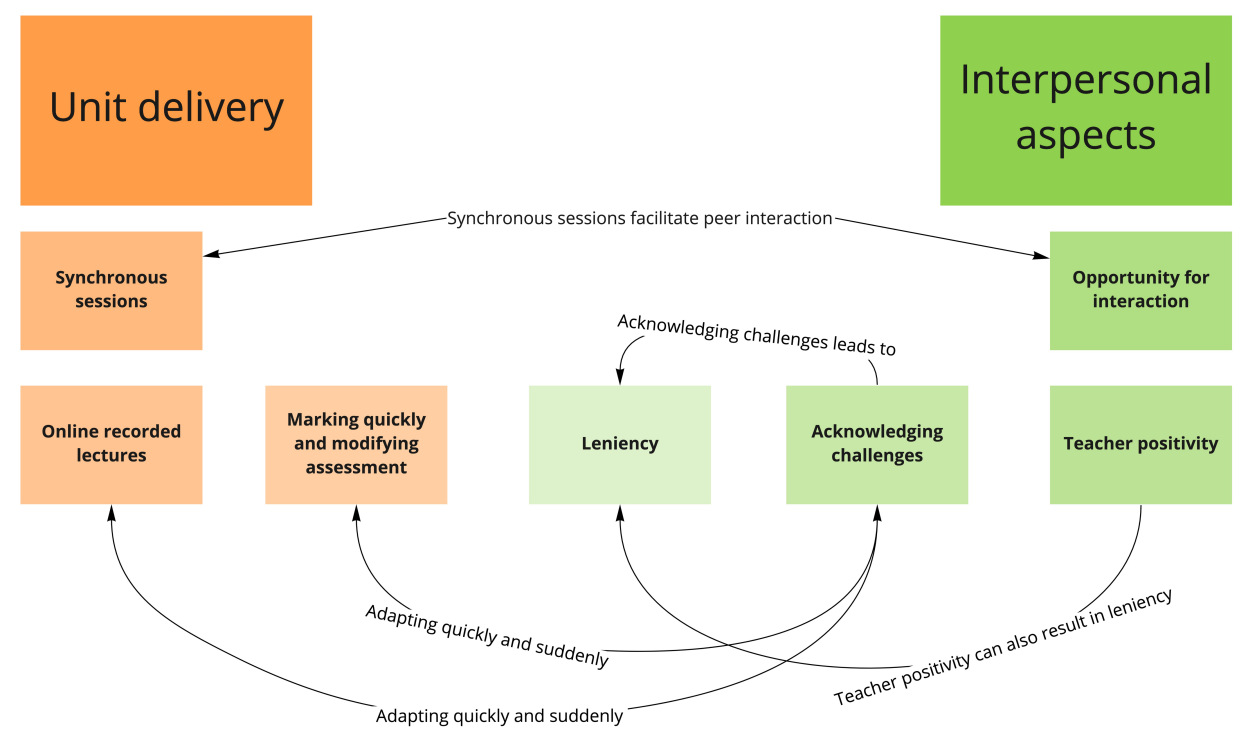

Figure 4. Relationship between the themes

\section{Discussion and conclusion}

The findings from this study are aligned with past research in this area. However, while most of the past studies reported in this paper focused on strategies and pedagogies of care, this paper focused on how the students perceived the pedagogies of care that were implemented. The findings align with the main objective of the 'pedagogy of care' which aims to ensure that students are aware they are cared for. Although the survey questions in this study did not directly ask the students about teacher care, it was clearly indicated in their responses that they were aware that their teachers cared for their learning and their wellbeing. This care according to Nel Noddings (1995) encourages students to themselves care for others and this was indicated in the comment by one of the students who stated that they were motivated 'to become a teacher who embeds so many valuable characteristics' as their tutor. The comment by this student also indicated that they were motivated to continue their study despite all the challenges, which is aligned with Teven and McCroskey (1997) stating that students who believe their teachers care for them are more likely to engage with the class. As mentioned above, Muller (2001) indicated that care is particularly important for at-risk students. In this unit, students were still transitioning from school to university when they were forced to shift to online learning. In addition, several students indicated that they were experiencing hardships such as family members passing away, a lack of motivation, unsuitability of the home environment and more, which could characterise these 
students as being at risk. The strategies adopted in this unit were similar to other educators' responses to the pandemic. In particular, the weekly synchronous sessions as well as flexibility or leniency towards students were also successfully implemented by Nasr (2020). The strategy to modify the assessment to reduce the impact of the pandemic on students was also reportedly adopted by Brown (2020) and Vasquez (2020).

The main limitation of this study was the small number of participants who were surveyed. However, the qualitative data from the survey was rich which compensated for this limitation. In addition, the survey was reported in this paper within the larger context of the case study which provided a more complete background and a description of the pedagogies of care that were implemented in this unit. Furthermore, the aim of this study is not to generalise the findings, but to provide an example of the implementation of pedagogies of care and a snapshot of students' experience of transitioning to online learning during the pandemic. These results are of value as they exhibit the student voice and how they perceived care.

\section{A way forward}

Moving forward, we need to rethink how we relate to our students in higher education. Caring for our students should be an explicit strategy implemented at different levels including the design of new units of study as well as locally through direct interaction with the students in classrooms. More priority should be given to building stronger and more authentic relationships with our students. Grounding our teaching practices in care can also lead to and encourage more creative instructional choices, including involving students in the design of tasks and activities, and designing more authentic assessments. The lessons learned from the implementation of a pedagogy of care will have significant implications for educators moving forward in a post-COVID world.

\section{References}

Brown, S. (2020). Teaching science methods online during COVID-19: Instructor's segue into online learning. Electronic Journal for Research in Science \& Mathematics Education, 24(3), 14-18.

Clarke, V., \& Braun, V. (2013). Teaching thematic analysis: Overcoming challenges and developing strategies for effective learning. The psychologist, 26(2), 120-123.

Doyle, L. H., \& Doyle, P. M. (2003). Building schools as caring communities: Why, what, and how? The Clearing House, 76(5), 259-261.

Fackler, A. K., \& Sexton, C. M. (2020). Science teacher education in the time of COVID-19: A document analysis. The Electronic Journal for Research in Science \& Mathematics Education, 24(3), 5-13.

Ferdig, R.E. \& Pytash, K.E. (2021). What teacher educators should have learned from 2020. Association for the Advancement of Computing in Education (AACE). https://www.learntechlib.org/primary/p/219088/

Hamilton, L., \& Corbett-Whittier, C. (2012). Using case study in education research. Sage.

Kim, M., \& Schallert, D. L. (2011). Building caring relationships between a teacher and students in a teacher preparation program word-by-word, moment-by-moment. Teaching and Teacher Education, 27(7), 10591067.

Lavy, S., \& Naama-Ghanayim, E. (2020). Why care about caring? Linking teachers' caring and sense of meaning at work with students' self-esteem, well-being, and school engagement. Teaching and Teacher Education, 91. doi: https://doi.org/10.1016/j.tate.2020.103046

Muller, C. (2001). The role of caring in the teacher-student relationship for at-risk students. Sociological Inquiry, 71(2), 241-255. doi: https://doi.org/10.1111/j.1475-682X.2001.tb01110.x

Nasr, N. (2020). Teachers as students. The Electronic Journal for Research in Science \& Mathematics Education, 24(2), 168-171.

Noddings, N. (1995). Teaching themes of care. Phi Delta Kappan, 76(9), 675-679.

Noddings, N. (2012). The caring relation in teaching, Oxford Review of Education, 38(6), 771-781, DOI: $10.1080 / 03054985.2012 .745047$

Teven, J. J., \& McCroskey, J. C. (1997). The relationship of perceived teacher caring with student learning and teacher evaluation. Communication Education, 46(1), 1-9.

Vasquez, S. (2020). Developing an online learning environment for community college students enrolled in human anatomy \& physiology and microbiology courses amid the COVID-19 pandemic. The Electronic Journal for Research in Science \& Mathematics Education, 24(3), 53-59. 
Wardak, D. (2021). Implementing pedagogies of care in online teacher education. In Gregory, S., Warburton, S., \& Schier, M. (Eds.), Back to the Future - ASCILITE '21. Proceedings ASCILITE 2021 in Armidale (pp. 319328). DOI: https://doi.org/10.14742/ascilite2021.0146

Note: All published papers are refereed, having undergone a double-blind peer-review process.

The author(s) assign a Creative Commons by attribution licence enabling others to distribute, remix, tweak, and build upon their work, even commercially, as long as credit is given to the author(s) for the original creation.

(c) Wardak, D. 2021 